\title{
The Value of BRCA 1 Gene Mutation in Patients with Breast Cancer
}

\author{
Shimaa A. Rashed, Osama B. Seddek, Hasnaa A. Abo-ELwafa and Abeer M. \\ Mohamed
}

Department of Clinical Pathology, Faculty of Medicine, Sohag University

\section{Abstract}

Introduction: Breast cancer (BC) is the most common malignant tumor in females in almost all of countries with highest age-adjusted incidence in developed countries (73\%) and includes the $23 \%$ of all types of cancers. World Health Organization (WHO) report shows that this prevalence rising $2 \%$ per year. As a matter of fact, $\mathrm{BC}$ is responsible for most of deaths due to cancer in women all over the world. According to surveys which were globally conducted, the overall rate of $\mathrm{BC}$ is higher in American and European women compared to the Asian, and it may be related to the life style of Asian population.

Aim of the work: Aim of this work was to determine the diagnostic value of BRCA1 gene mutations in female patients with breast cancer, also to correlate them with the presence or absence of family history of breast cancer and to allow identification of individuals at high risk.

Patients and Methods: The study was carried on fifty women, included twenty-five female patients with breast cancer presented to Medical Oncology Department at Sohag University Hospital from 2015 to 2017, their age ranged from (25-70 years). Patients were diagnosed by clinical examination and confirmed by mammography and surgical biopsies; fine needle aspiration cytology (FNAC) or core needle biopsy (CNB) and CA15-3. Other twenty-five women were healthy control not relatives to the patients.

Results: Our study suggested that the prevalence of BRCA 1 mutations is lower in Sohag Conclusion: Also, the low percentage of the 185delAG mutation in BRCA1 in BC suggested that is insufficient to justify screening in the Egyptian population. Our study suggested that the prevalence of BRCA 1 mutations is lower in Sohag. So, complete BRCA 1 genes sequence analysis might be required for identification of specific mutation in Egyptian. .

Key words: BRCA 1, mutation, Breast Cancer.

\section{Introduction}

$\mathrm{BC}$ is the most common malignant tumor in females in almost all of countries with highest age-adjusted incidence in developed countries $(73 \%)$ and includes the $23 \%$ of all types of cancers. WHO report shows that this prevalence increases $2 \%$ per year ${ }^{(1)}$. As a matter of fact, $\mathrm{BC}$ is responsible for most of deaths due to cancer in women worldwide. According to studies which were globally done, the rate of $\mathrm{BC}$ is higher in American and European women compared to the Asian, and it may be related to the life style of Asian population. The main type of $\mathrm{BC}$ is found to be sporadic with estimated frequency from $90 \%$ to $95 \%$, and the rest (5-10\%) includes the familial Breast cancer $^{(2)}$.

Many risk factors are present: - Non genetic risk factors: age, hormonal factors (estrogen and progesterone), life style, other factors (obesity, diet, physical activity, sleep rhythm and night shifts, smoking), certain viral infection, local breast factors such as high breast density and presence of local breast pathology\& genetic risk factors: presence of family history of $\mathrm{BC}$ and presence of susceptibility genes e.g. BRCA1, BRCA2. Malignant 
transformation arise from accumulation of mutations that are frequently associated with molecular anomalies in such tumor-suppressor genes, as a result of genetic susceptibility and/or exposure to physical, chemical, biological or environmental factors. Three BRCA genes mutations; 185delAG, 5382insC, and 6174delT, are commonly present in Ashkenazi Jewish individuals and in general population. There is a strong correlation between the inactivation of BRCA 1 and BRCA 2 and tumor phenotype ${ }^{(3)}$. Identification of BRCA1 and BRCA2 has led to main changes in the treatment of women with inherited susceptibility to breast and ovarian cancer. The original feature of these clinical changes has been the genetic method to identification of highrisk women. The medical and surgical choices offered to high-risk women remain predictable. Ultimately, one hopes that understanding the pathways in which BRCA1 and BRCA2 participate in normal breast cells and in breast tumorigenesis will become the basis of non-invasive intervention for women at hazard $^{(4)}$.

\section{Aim of the work:}

Aim of this work was to detect the diagnostic value of BRCA 1 gene mutations in female patients with $\mathrm{BC}$, also to correlate them with the presence of family history of $\mathrm{BC}$ and to allow identification of individuals at high risk.

\section{Patients and Methods:}

\section{Patients:}

The study was carried on fifty women, included twenty-five female cases with $\mathrm{BC}$ with no family history of $\mathrm{BC}$ in their first degree relatives presented to Medical Oncology Department at Sohag University Hospital from 2015 to 2017, their age ranged from (25-70 years). Patients were diagnosed by clinical examination and confirmed by mammography and surgical biopsies; (FNAC) or (CNB) and CA15-3. Other twenty-five women were healthy control not relatives to the patients.

\section{Methods:}

All groups were subjected to the following:

\section{History taking including:}

- Age and menstrual status.

- Family history of breast cancer.

- Clinical presentation.

- Marital status.
- Parity and lactation.

- Time of diagnosis and status of treatment.

2. Clinical examination including careful examination of the breast and the axillary lymph nodes.

ONLY the patient groups (Group I \& GroupII) were subjected to:

3. Mammography: To confirm presence of breast mass.

4. FNA biopsy or CNB: Followed by pathological examination to confirm the presence of malignancy.

5. Metastatic work up:

- Chest X ray and/or CT scan.

- Bone scan.

\section{Laboratory Investigations:}

\section{Sample Collection:}


$10 \mathrm{ml}$ of venous blood was withdrawn into three vacutainer tubes were taken through venipuncture under a complete aseptic technique.

a. The first tube contains two ml of blood on EDTA (Ethylene diaminetetra acetic acid) purple capped vacutainer tube for CBC (Complete Blood Count), ESR (Erythrocyte sedimentation rate).

b. The second one contains five milliliters of blood on plain red capped

\section{A-CA 15-3 Assay:}

By chemiluminescent microparticle immunoassay (CMIA) method for the quantitative determination of DF3 defined antigen in human serum and plasma on ARCHITECT iSYSTEM.

B- BRCA1 (1850del) mutation using PCR technique the following steps were done

1. DNA Extraction

\section{Amplification of DNA}

3. Detection of Gene Mutation by Gel Electrophoresis.

\section{1- DNA Extraction:}

\section{Kit used:}

We used By the use of Quick-DNA ${ }^{\mathrm{TM}}$ Miniprep Kit (Catalog No D3024)

\section{The Steps of DNA Extraction:}

1-400 $\mu \mathrm{L}$ of Genomic Lysis Buffer were added to $200 \mu \mathrm{L}$ of the blood sample into a Zymo-Spin Column in a Collection Tube and centrifuged for one minute at $10,000 \mathrm{rpm}$. The Collection Tube was discarded with the flow through. vacutainer tube, after clotting; the serum was separated by centrifugation for 10 minutes at 4,000 rpm and then was used for assessment of routine chemistry tests (RFT, LFT, and CA 15-3).

c. The third tube contains $3 \mathrm{ml}$ on EDTA capped vacutainer for DNA extraction .

\section{Specific Investigations:}

2-The Zymo-Spin Column was transferred carefully to a new Collection Tube. Then $200 \mu \mathrm{L}$ of DNA Pre-Wash Buffer was added to the Spin Column and mixed by pulsevortexing for 15 seconds. Then centrifuged at $10,000 \mathrm{rpm}$ for one minute.

3-500 $\mu \mathrm{L}$ of DNA Wash Buffer was added to the Spin Column. Then centrifuged at10,000 rpm for one minute.

4- The Spin Column was transferred to a clean microcentrifuge tube and 50 $\mu$ L DNA Elution Buffer was added to the Spin Column. Then incubated for 2-5 min at room temp to increase the DNA yield, and then centrifuged at top speed for 30 seconds to elute the DNA.

\section{Optimization of PCR:}

The cycling conditions were as follows:

An initial denaturation for $5 \mathrm{~min}$ at $95^{\circ} \mathrm{C}$, followed by 35 cycles at $94^{\circ} \mathrm{C}$ for $30 \mathrm{~s}, 57^{\circ} \mathrm{C}$ for $30 \mathrm{~s}$ and $72^{\circ} \mathrm{C}$ for 45 s. The final extension step was at $72^{\circ} \mathrm{C}$ for $10 \mathrm{~min}$. 


\section{Results}

The mean age in BC group was 48.68 with SD 12.30 years with range 29-68 years which was older than control group as its mean age was 42.96 with SD 14.0 years with range 24-68 years, with non-significant difference.

The mean age of menarche in BC group was 12.00 with SD 1.803 years with range also 9-15 years which was non-significant different from mean age of menarche in control group as it was 12.19 with SD 1.32 years with range 10-15 years. There was high significant difference ( $\mathrm{p}$ value $<0.001$ ) between the studied groups as regards parity. Majority of BC cases $(68 \%)$ had 4 children; however $44 \%$ of controls were singles.

\section{Association between different reproductive factors and BC:}

None of different reproductive factors enrolled in the present study was significantly associated with the occurrence of $\mathrm{BC}$ except the marital state. There was significant difference between $\mathrm{BC}$ and controls according to marital state. There was significant increase of married patients in SBC (96\%) but in controls (56\%) (p value $<0.001$ ).

There was non-significant difference between groups regarding use of contraception, $52 \%$ of BC group and only $32 \%$ of controls were using contraception. There was also non-significant difference between groups regarding menopausal state, $52 \%$ of sporadic group were premenopausal but controls included $64 \%$ premenopausal.

There was also non-significant difference between groups regarding breastfeeding, $76 \%$ of BC group and only $56 \%$ of controls were breast feed (Table 1).

Table 1. Distribution of studied groups according to marital state, use of contraception, menopausal status and breast feeding

\begin{tabular}{|c|c|c|c|c|c|}
\hline \multicolumn{2}{|c|}{ Reproductive factors } & \multirow{2}{*}{$\begin{array}{c}\text { BC } \\
\text { No. (\%) } \\
24(96 \%)\end{array}$} & $\begin{array}{l}\text { Control } \\
\text { No. }(\%)\end{array}$ & \multirow[t]{2}{*}{ Chi square } & \multirow[t]{2}{*}{$P$ value } \\
\hline Marital state & Married & & $14(56 \%)$ & & \\
\hline & Single & $1(4 \%)$ & $11(44 \%)$ & 18.000 & $<0.001(\mathrm{HS})$ \\
\hline \multirow{2}{*}{$\begin{array}{c}\text { Use of } \\
\text { contraception }\end{array}$} & Yes & $13(52 \%)$ & $8(32 \%)$ & \multirow[b]{2}{*}{4.167} & \multirow[b]{2}{*}{$0.244(\mathrm{NS})$} \\
\hline & No & $12(48 \%)$ & $17(68 \%)$ & & \\
\hline \multirow{2}{*}{$\begin{array}{c}\text { Menopausal } \\
\text { status }\end{array}$} & Pre & $13(52 \%)$ & $16(64 \%)$ & \multirow[b]{2}{*}{4.478} & \multirow[b]{2}{*}{$0.214(\mathrm{NS})$} \\
\hline & Post & $12(48 \%)$ & $9(36 \%)$ & & \\
\hline \multirow[t]{2}{*}{ Breast feeding } & Yes & $19(76 \%)$ & $14(56 \%)$ & \multirow[b]{2}{*}{2.242} & \multirow[b]{2}{*}{$0.524(\mathrm{NS})$} \\
\hline & No & $6(24 \%)$ & $11(44 \%)$ & & \\
\hline
\end{tabular}


As regards site of tumor, $72 \%$ of BC group had unilateral tumor and only $28 \%$ of BC group had bilateral tumor.

There were only 3 cases (12\%) of BC group had metastases. There was nonsignificant difference between $\mathrm{BC}$ and controls as regards CBC (WBCs, HB, PLTs) when compared to controls.

There was high significant difference ( $\mathrm{p}$ value $<0.001)$ between groups as regards ESR as $100 \%$ of BC group had high ESR and none of control group had high ESR.

There was non-significant difference between $\mathrm{BC}$ and controls as regards liver function tests which include alanine aminotransferase (ALT), aspartate aminotransferase (AST), total protein, albumin, total bilirubin (TBIL), direct bilirubin (Direct BIL) and alkaline phosphatase (ALP) when compared to controls. On the other hand, there was high significant increase in urea in $\mathrm{BC}$ group when compared to controls ( $p$ value $<0.001$ ), also there was significant increase in creatinine in BC group when compared to relatives and controls ( $\mathrm{p}$ value $=0.02$ ).

\section{Specific investigations.}

\section{CA 15-3}

There was high significant increase in CA 15-3 in BC group when compared to controls ( $\mathrm{p}$ value $<0.001$ ) (Table 2).

Table 2. CA 15-3 of the studied groups.

\begin{tabular}{ccccc}
\hline & $\begin{array}{c}\text { BC } \\
\text { group } \\
\text { Mean } \pm \text { SD }\end{array}$ & $\begin{array}{c}\text { Control } \\
\text { group } \\
\text { Mean } \pm \text { SD }\end{array}$ & ANOVA & P value \\
\hline $\begin{array}{c}\text { CA 15-3 } \\
(\mathbf{U} / \mathbf{m l})\end{array}$ & $201.08 \pm 131.6$ & $12.08 \pm 2.87$ & $33.807^{*}$ & $<\mathbf{0 . 0 0 1}$ (HS) \\
\hline
\end{tabular}

\section{BRCA1 gene (185delAG mutation)}

There was only (1 case/ $4 \%$ ) in BC group had heterozygous BRCA1 gene (185delAG mutation), this mean that total prevalence of BRCA1 gene (185delAG mutation) in $\mathrm{BC}$ was $4 \%$ (Table 3 ). 
Table 3. BRCA1 gene (185delAG mutation) in the studied groups

\begin{tabular}{clccc} 
& & \multicolumn{2}{c}{ Group } & Total \\
\cline { 3 - 5 } Negative & NO.of Cases & BC & Control & 96 \\
(not present) & \% within BRCA1 & 24 & 25 & $100 \%$ \\
& \% within group & $25.0 \%$ & $26.0 \%$ & $96.0 \%$ \\
Heterozygous & NO.of Cases & $96.0 \%$ & $100.0 \%$ & 3 \\
185delAG mutation & \% within BRCA1 & 1 & 0 & $100 \%$ \\
& \% within group & $33.3 \%$ & $0.0 \%$ & $3.0 \%$ \\
Homozygous & NO.of Cases & $4.0 \%$ & $0.0 \%$ & 1 \\
185delAG mutation & \% within BRCA1 & 0 & 0 & $100 \%$ \\
& \% within group & $0.0 \%$ & $0.0 \%$ & $1.0 \%$ \\
Total & NO.of Cases & $0.0 \%$ & $0.0 \%$ & 100 \\
& \% within BRCA1 & 25 & 25 & $100 \%$ \\
& \% within group & $25.0 \%$ & $25.0 \%$ & $100 \%$ \\
\hline
\end{tabular}

Chi square $=5.573, \mathrm{P}$ value $=0.637(\mathrm{NS})$

\section{Discussion}

Our study included 50 females, divided to 2 groups, first group included 25 cases (BC), and second group included 25 controls.

The mean age in BC group was 48.68 with SD 12.30 years with range 29-68 years which was older than control group as its mean age was 42.96 with SD 14.0 years with range 24-68 years, with non-significant difference.

In our study, the mean age of menarche in BC group was 12.00 with SD 1.803 years with range also 9-15 years which was non-significant different from mean age of menarche in control group as it was 12.19 with SD 1.32 years with range 10-15 years.

In study of Knudson. ${ }^{(5)}$ they found that young age of menarche (before 13 years) was found to be associated with increased hazard of $\mathrm{BC}$ especially in susceptible women. This may be related to a higher life time exposure to the hormones estrogen and progesterone.

Our results were similar to results of Jalkh et al. ${ }^{(6)}$ as mean age in their study at diagnosis of $\mathrm{BC}$ for the seventy-two patients was 41 years old. In study of Peto et al. ${ }^{(7)}$ fifteen $(5.9 \%)$ of 254 women diagnosed with breast cancer before age 36 years and 15 $(4.1 \%)$ of 363 females diagnosed from ages 36 years through 45 years carried mutations in BRCA1.

In this study there was high significant difference ( $p$ value $<0.001$ ) between the studied groups as regards parity. Majority of BC cases $(68 \%)$ had 4 children, however $44 \%$ of controls were singles.

In this study none of different reproductive factors enrolled in the present study was significantly associated with the occurrence of BC except the marital state. There was significant difference between $\mathrm{BC}$ and controls according to marital state. There was significant increase of married patients in BC $(96 \%)$ than controls $(56 \%)$ ( $\mathrm{p}$ value $<0.001$ ).

We found that there was nonsignificant difference between groups regarding use of contraception, $52 \%$ of BC group, however only $32 \%$ of controls were using contraception. There was also non-significant difference between groups regarding 
menopausal state, $52 \%$ of $\mathrm{BC}$ group were premenopausal but controls included $64 \%$ premenopausal.

It has been suggested that breast feeding may protect against $\mathrm{BC}$ and increasing years of nursing experience may decrease the $\mathrm{BC}$ risk but in the present study there was non-significant difference between groups as regards breastfeeding, $76 \%$ of $\mathrm{BC}$ group, and only $56 \%$ of controls were breast feed.

In this study, there was nonsignificant difference between groups as regards routine laboratory investigations (WBCs, HB, PLTs, ALT, AST, T. protein, Albumin, T .bil, Direct. Bil and ALP). However there was high significant difference between groups as regards both ESR and CA 15.3 as $100 \%$ of sporadic group had high ESR, and none of control group had high ESR. On the other hand, mean of CA 15.3 was higher in BC group $(190.40 \pm 124.7)$ than control group (12.08 \pm 2.87$)$.

We found that total prevalence of BRCA1 gene 185delAG mutation in $\mathrm{BC}$ was 4\% (1 case). Our results about prevalence of BRCA1 gene was lower than that in study of Jalkh et al. ${ }^{(6)}$ who identified BRCA1 185delAG mutations in 9 carriers among a cohort of 72 unrelated Lebanese patients with $\mathrm{BC}$, providing a frequency of mutations which represents a prevalence of $12.5 \%$. The low prevalence of mutations found in their population in comparison to other ones $(8,9)$, can be explained either by the genetic testing criteria, or by the possibility that some mutations were missed since they could not look for deletions or duplications of entire exons. Consanguinity might be also an equivocal risk modifying factor ${ }^{(10,11)}$.

Other studies on Iranian also could not detect any mutations in this population ${ }^{(12)}$. Gomes et al. ${ }^{(13)}$ carried out a pioneering, case-control study on the incidence of BRCA 1 and BRCA 2 mutations in patients with breast cancer in the State of de Janeiro. These investigators reported a mutation prevalence of $2.3 \%$ which was lower than incidence in our study, suggesting that in every 50,000 cases of breast cancer diagnosed in Rio de Janeiro, 1000 are related to germ line mutations in these genes. In that study, most of the mutations $(50 \%)$ found were in $185 \mathrm{delAG}$ of the BRCA 1 gene, Gomes et al. ${ }^{(13)}$ failed to find the ins $6 \mathrm{~kb}$ mutation in any of their cases, probably due to the differences in the characteristics of the studied populations.

Juwle and Saranath. investigated BRCA1 mutations and BRCA1 haplotypes in early BC patients and their relatives, sporadic breast cancers patients, and normal healthy controls 50 years, in women of Indian origin. They observed BRCA 1 185 delAG gene mutations, deleterious mutations and unorganized variants, in a relatively higher proportion of $52 \%$ early BC patients. BRCA 1 mutations were not detected in sporadic breast cancer patients, although 3 unclassified variants in three individual cases were identified in the sporadic cancers. Deleterious mutations and unclassified variants were not detected in normal healthy control group. Earlier studies on women of Indian origin have reported 2.9-28\% of early BC patients with BRCA1 185delAG mutations ${ }^{(15}$, 16)

Ahn et al. (17) evaluated the prevalence of BRCA1185delAG mutations in high-risk patients as well as in unselected breast cancer patients in Korea, they found that the prevalence of these mutations was about 4-5 times higher in high risk patients than in unselected patients. Their finding of BRCA 1 mutations in $23 \%$ of Korean patients with a family history of $\mathrm{BC}$ is in good agreement with findings in Caucasian and other 
Asian patients, in whom BRCA1 mutations were detected in $11 \%$ to $33 \%$ of those with a family history of breast cancer ${ }^{(7,18,19)}$. In some of these

\section{Conclusion:}

Also, the low percentage of the 185delAG mutation in BRCA 1 in BC suggested that alone is insufficient to justify screening in the Egyptian population. Our study suggested that

\section{References:}

1. Parkin DM, Bray F, Ferlay J, Pisani P. Global cancer statistics, 2002. CA: a cancer journal for clinicians. 2005;55(2):74-108.

2. Silva SN, Tomar M, Paulo C, Gomes BC, Azevedo AP, Teixeira V, et al. Breast cancer risk and common single nucleotide polymorphisms in homologous recombination DNA repair pathway genes XRCC2, XRCC3, NBS1 and RAD51. Cancer epidemiology. 2010;34(1):85-92.

3. Kirchhoff T, Gaudet MM, Antoniou AC, McGuffog L, Humphreys MK, Dunning AM, et al. Breast cancer risk and 6q22.33: combined results from Breast Cancer Association Consortium and Consortium of Investigators on Modifiers of BRCA1/2. PloS one. 2012;7(6):e35706.

4. Jeyasekharan AD, Liu Y, Hattori H, Pisupati V, Jonsdottir AB, Rajendra E, et al. A cancer-associated BRCA2 mutation reveals masked nuclear export signals controlling localization. Nature structural \& molecular biology. 2013;20(10):11918.

5. Knudson AG. Two genetic hits (more or less) to cancer. Nature reviews Cancer. 2001;1(2):157-62. studies, $45 \%$ to $51 \%$ of patients with two or more relatives with sporadic BC were found to have BRCA1 mutations $(7,19)$

the incidence of BRCA 1 mutations is lower in Sohag. So, complete BRCA 1 genes sequence analysis might be required for identification of specific mutation in Egyptian.

6. Jalkh N, Nassar-Slaba J, Chouery E, Salem N, Uhrchammer N, Golmard L, et al. Prevalance of BRCA1 and BRCA2 mutations in familial breast cancer patients in Lebanon. Hereditary cancer in clinical practice. 2012;10(1):7.

7. Peto J, Collins N, Barfoot R, Seal S, Warren W, Rahman N, et al . Prevalence of BRCA1 and BRCA2 gene mutations in patients with earlyonset breast cancer. Journal of the National Cancer Institute. 1999;91(11):943-9.

8. Hall MJ, Reid JE, Burbidge LA, Pruss D, Deffenbaugh AM, Frye $\mathrm{C}$, et al. BRCA1 and BRCA2 mutations in women of different ethnicities undergoing testing for hereditary breast-ovarian cancer. Cancer. 2009;115(10):2222-33.

9. Uhrhammer N, Abdelouahab A, Lafarge L, Feillel V, Ben Dib A, Bignon YJ. BRCA1 mutations in Algerian breast cancer patients: high frequency in young, sporadic cases. International journal of medical sciences. 2008;5(4):197-202.

10. Liede A, Malik IA, Aziz Z, Rios Pd Pde L, Kwan E, Narod SA. Contribution of BRCA1 and BRCA2 mutations to breast and ovarian cancer in Pakistan. American journal of human genetics. 2002;71(3):595-606. 
11. Bener A, Ayoubi HR, Ali AI, Al-Kubaisi A, Al-Sulaiti H. Does consanguinity lead to decreased incidence of breast cancer? Cancer epidemiology. 2010;34(4):413-8.

12. Fattahi MJ, Mojtahedi Z, Karimaghaee N, Talei AR, Banani SJ, Ghaderi A. Analysis of BRCA1 and BRCA2 mutations in southern Iranian Breast cancer patients. Archives of Iranian medicine. 2009;12(6):584-7.

13. Gomes MC, Costa MM, Borojevic R, Monteiro AN, Vieira R, Koifman S, et al. Prevalence of BRCA1 and BRCA2 mutations in breast cancer patients from Brazil. Breast cancer research and treatment. 2007;103(3):349-53.

14. Juwle A, Saranath D. BRCA1/BRCA2 gene mutations/SNPs and BRCA1 haplotypes in early-onset breast cancer patients of Indian ethnicity. Medical oncology. 2012;29(5):3272-81.

15. Saxena S, Chakraborty A, Kaushal M, Kotwal S, Bhatanager D, Mohil RS, et al. Contribution of germline BRCA1 and BRCA2 sequence alterations to breast cancer in Northern India. BMC medical genetics. 2006;7:75.

16. Vaidyanathan $\mathrm{K}$, Lakhotia $\mathrm{S}$, Ravishankar HM, Tabassum U, Mukherjee G, Somasundaram K.
BRCA1 and BRCA2 germline mutation analysis among Indian women from south India: identification of four novel mutations and highfrequency occurrence of $185 \mathrm{del} \mathrm{AG}$ mutation. Journal of biosciences. 2009;34(3):415-22.

17. Ahn SH, Hwang UK, Kwak BS, Yoon HS, Ku BK, Kang HJ, et al. Prevalence of BRCA1 and BRCA2 mutations in Korean breast cancer patients. Journal of Korean medical science. 2004;19(2):269-74.

18. Malone KE, Daling JR, Neal C, Suter NM, O'Brien C, Cushing-Haugen $\mathrm{K}$, et al. Frequency of BRCA1/BRCA2 mutations in a population-based sample of young breast carcinoma cases. Cancer. 2000;88(6):1393-402.

19. Frank TS, Deffenbaugh AM, Reid JE, Hulick M, Ward BE, Lingenfelter $\mathrm{B}$, et al. Clinical characteristics of individuals with germline mutations in BRCA1 and BRCA2: analysis of 10,000 individuals. Journal of clinical oncology : official journal of the American Society of Clinical Oncology. 2002;20(6):1480-90. 